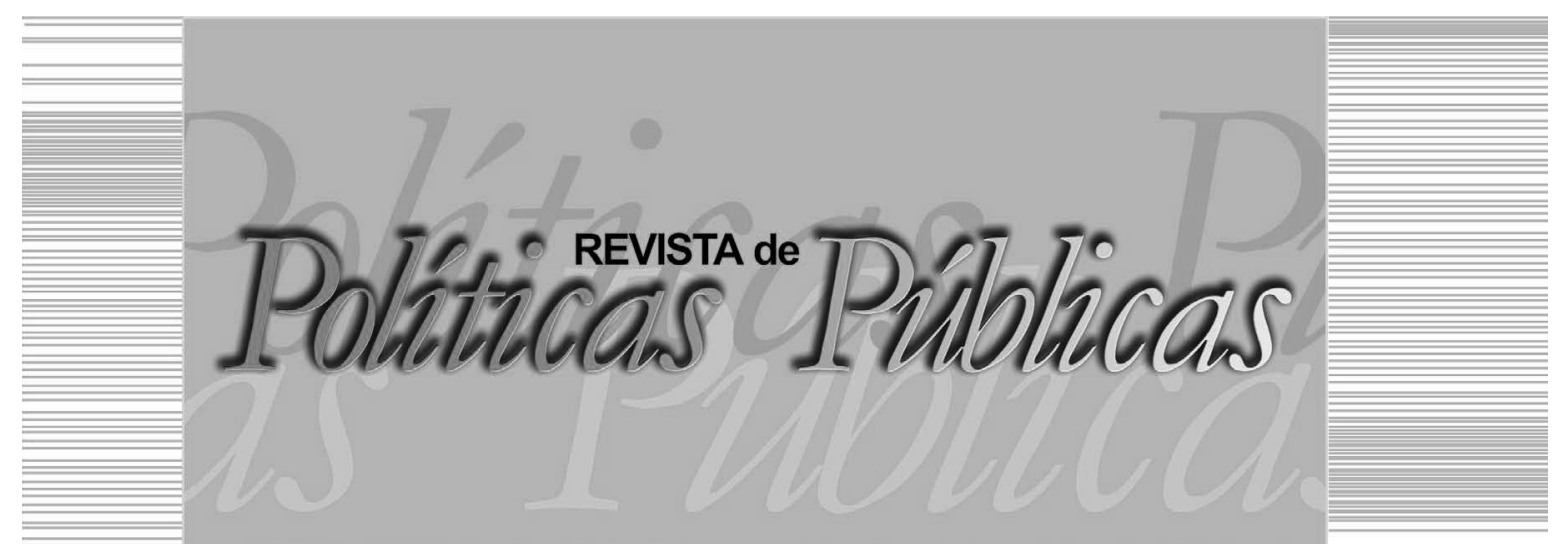

\title{
O GRITO QUE RECLAMA PAZ: o legado da Revolução Russa para a luta das mulheres
}

\author{
Daniela Ribeiro Castilho \\ Esther Luiza de Souza Lemos ${ }^{2}$ \\ Vera Lucia Batista Gomes ${ }^{3}$
}

\section{Resumo}

Este artigo enfatiza o debate sobre a luta e a defesa dos direitos das mulheres, em especial, com relação ao processo social contemporâneo, de avanço e aceleração das contrarreformas trabalhista e previdenciária, a partir do legado histórico construído pelas mulheres russas e seu protagonismo e vanguarda da Revolução Socialista de 1917. Por meio da análise do tempo histórico, busca problematizar o nexo e as particularidades de tais contextos e sua importância no atual cenário econômico, político, social e cultural em que se vive. Por fim, conclui que as contradições nas sociedades capitalistas são vivenciadas pelas mulheres trabalhadoras com muito mais intensidade no cenário contemporâneo de acirramento da luta de classes, por meio da aceleração do desmonte de todo o sistema protetivo brasileiro, impelindo a classe trabalhadora às condições de vida cada vez mais degradantes e desumanas.

1 Assistente Social, Doutora em Serviço Social pela Universidade Federal do Rio de Janeiro (UFRJ), Professora da Faculdade de Serviço Social da Universidade Federal do Pará (UFPA).Email: danicastilho@ufpa.br

2 Assistente Social, Doutora em Serviço Social pela UFRJ, Professora do Curso de Serviço Social da Universidade Estadual do Oeste do Paraná (UNIOESTE) - Toledo/ PR e Coordenadora do Programa de Pós-Graduação em Serviço Social (PPGSS) da UNIOESTE. Email: estherlemos@gmail.com / Universidade Estadual do Oeste do Paraná - UNIOESTE: R. Universitária, 1619, Universitário Cascavel - PR. CEP: 85819-110.

3 Assistente Social, Doutora em Sociologia do Trabalho pela Université de Picardie Jules Vernes (França), Professora da Faculdade de Serviço Social e Coordenadora do Programa de Pós-Graduação em Serviço Social (PPGSS) da UFPA. Email: veragomesbelem@ hotmail.com / Universidade Federal do Pará - UFPA: Rua Augusto Côrrea, , 01, Guamá Belém/PA. CEP: 66075-110. 
Palavras-chave: Revolução socialista, mulher, contrarreforma, direitos sociais, trabalho.

THE SCREAM THAT CLAIMS PEACE: the legacy of the Russian Revolution for women's struggle

\begin{abstract}
This article emphasizes the debate on the struggle and defense of women's rights, especially in relation to the contemporary social process, of advancing and accelerating the labor and social security counter-reforms, based on the historical legacy built by Russian women and their protagonism and vanguard of the Socialist Revolution of 1917. Through the analysis of historical time it is sought to problematize the nexus and the particularities of such contexts and their importance in the current economic, political, social and cultural scenario that is lived. Finally, it is concluded that the contradictions in capitalist societies are experienced by working women with much more intensity in the contemporary scenario of the intensification of the class struggle, by accelerating the dismantling of every Brazilian protective system, impelling the working class to conditions of life more degrading and inhuman.

Key words: Socialist revolution, woman, counter-reformation, social rights, work.
\end{abstract}

\title{
1 INTRODUÇÃO
}

O debate sobre as conquistas, lutas e limites na efetivação dos direitos dos e das trabalhadoras no capitalismo contemporâneo nos convoca e nos provoca a pensar o protagonismo das mulheres ao longo do século XX e XXI. Na conjuntura atual vivenciamos o arrefecimento, o adensamento e a intensificação do desmonte de conquistas históricas, em especial, no Brasil, de direitos sociais, a partir da década de 1930, incidindo em mudanças regressivas no presente marco regulatório.

Nossa análise tem como fio condutor o legado deixado pelas mulheres revolucionárias no período da Revolução Russa de 1917, que naquele momento foram às ruas reivindicar pão e paz,para a luta e organização das mulheres trabalhadoras no Brasil, em 2017. São cem anos de legado, de aprendizado e de história que possibilitam reflexões profundas acerca do papel decisivo das mulheres para a construção das condições objetivas e subjetivas que constituíram a base para a tomada do poder e a instalação do governo dos sovietes. 
Tal conquista viabilizou avanços que nenhuma experiência capitalista pode alcançar.

O fundamento da análise baseia-se na Teoria Social de Marx e no seu método que possibilita uma visão totalizante do real e nos permite apreender as determinações históricas, sociais, econômicas, políticas e culturais conectadas a uma mesma totalidade. Esta se apresenta por meio de múltiplos e diversos níveis de totalização que podem ser entendidos e apreendidos pelo pensamento conforme o grau de generalização e do propósito do(a) pesquisador(a). (KONDER, 1991).

Nesse sentido, o presente texto tem como objetivo apreender o contexto vivido pelas mulheres na Rússia revolucionária do início do século XX, suas lutas e conquistas que inspiram a necessária e urgente revolução das condições da mulher em nível mundial, em tempos de capital fetiche. A história da Revolução Russa é a história da classe trabalhadora e, nesta, de milhares de mulheres operárias, de garra e coragem, que tiveram papel decisivo no sucesso da revolução de outubro de 1917.

Tais conquistas influenciaram a luta das mulheres no mundo todo, particularmente nas sociedades capitalistas, por meio da constituição de estratégias de enfrentamento que se materializaram na organização destas em partidos políticos, sindicatos, associações e movimentos sociais da classe trabalhadora, tendo como pauta central a igualdade de condições e oportunidades entre homens e mulheres. Como bem afirma Clara Zetkin (1976, p. 107) em Congresso da III Internacional Comunista, "[...] nenhuma agitação especificamente feminista senão agitação socialista entre as mulheres. Não devemos pôr em primeiro plano os interesses mais mesquinhos do mundo da mulher: nossa tarefa é a conquista da mulher proletária para a luta de classes".

Aqui é importante frisar que tal como em 1917, a luta e emancipação das mulheres no contexto atual só pode se dar por meio da organização destas em organismos e instrumentos construídos pela classe trabalhadora. A efetivação das conquistas em sua plenitude só pode se realizar a partir da construção de uma nova ordem societária sem explorados(as) e exploradores(as); sem machismo; sem patriarcalismo e sem opressões. Essa perspectiva foi apontada nos princípios e táticas no trabalho realizado entre as mulheres durante o III Congresso da Internacional Comunista, quando orientava que, 
o que o comunismo pode dar às mulheres, o movimento feminino burguês não poderá dar.

\section{REVOLUÇÃO RUSSA E O PROTAGONISMO DAS MULHERES NA LUTA POR DIREITOS: conquistas no marco regulatório}

O ano era 1905, e a Rússia Czarista vivia um processo de transição do feudalismo para o capitalismo por conta das mudanças econômicas que suscitaram o interesse do capital estrangeiro e fomentaram um processo acelerado de industrialização, em especial em Moscou, São Petersburgo e Ucrânia, o que possibilitou a constituição de um contingente expressivo de operariado urbano que pressionava por melhorias de condição de vida e reformas democráticas. Esse cenário se complexificou com a atuação catastrófica do exército russo na guerra contra o império japonês pela disputa dos territórios da Coréia e Manchúria. (SOUZA, 2012).

Greves, manifestações e protestos explodiam contra o governo czarista de Nicolau II, exigindo a imediata retirada do exército russo e o retorno dos soldados ao país.Um dos momentos mais marcantes ocorreu num domingo de 1905, quando milhares de trabalhadores/as e crianças marcharam pacificamente em direção ao Palácio de Inverno para entregar uma pauta de reivindicações ao czar Nicolau II, exigindo direitos e melhores condições de vida e de trabalho para o povo.

Foram recebidos/as com balas de canhão e fuzis num verdadeiro ato de repressão e violência que ficou conhecido na história como domingo sangrento. Em segundos, milhares de corpos foram amontoados, inertes no gélido chão de São Petersburgo. A morte soou como fagulhas ao vento, dando início a um processo que culminaria com a revolução de outubro de 1917.

Mas voltemos a 1905, pois lá se encontrava no meio da multidão uma mulher que teria um papel central na condução e na consolidação de uma revolução socialista e feminista. Estamos falando de Alexandra Kollontai (1872-1952) que se encontrava presente na manifestação; ela viu e sentiu na pele a reação bruta e violenta do czarismo.

Tal acontecimento marcaria profundamente sua vida e determinaria sua posição de classe e trajetória política. Segundo seus 
relatos, essa cena ficaria eternamente em sua memória. Em muitas reportagens e conferências costumava dizer: "Vi milhares de crianças mortas a tiro ou feridas além da possibilidade de sobrevivência". A mulher Alexandra Kollontai vai ser, após a tomada de poder pelos sovietes, já no cargo de Comissária Nacional da Seguridade Pública, a defensora e implementadora aguerrida de políticas e programas de proteção social às mulheres russas.

O domingo sangrento abriu o caminho para manifestações, motins e insurreições por toda a Rússia, com a formação de comitês revolucionários por bairros e fábricas, desembocando na tomada de poder pelos bolcheviques.

Um dos acontecimentos cruciais para o desencadear da revolução de 1917 foi liderado pelas trabalhadoras da indústria têxtil (o setor com maior grau de exploração e degradação humana) que mobilizaram mais de cem mil operárias num ato público no dia internacional da mulher e que clamavam por pão para nossos filhos e paz. Trotsky (1977, p. 102, grifo do autor) descreve bem esse momento em seu livro História da Revolução Russa quando expressa

\footnotetext{
[...] 23 de fevereiro ( 8 de março), era o dia internacional das mulheres, estavam programados atos, encontros etc. Mas não imaginávamos que este "dia das mulheres" viria a inaugurar a revolução. Estava planejado ações revolucionárias mas sem data prevista. Mas pela manhã, a despeito das diretivas, as operárias têxteis deixam o trabalho de várias fábricas e enviam delegadas para solicitarem sustentação da greve [...] o que se transforma em greve de massas $[\ldots]$ todas descem às ruas.
}

As condições de vida das mulheres trabalhadoras eram as piores, pois ganhavam pelo mesmo trabalho que os homens, menos da metade que estes. Havia ainda um grau de analfabetismo muito grande entre as operárias da indústria têxtil, cerca de $62 \%$. Concentravam-se nas indústrias têxteis e de alimentos, onde havia um grau maior de exploração. Além de estarem nas atividades laborais, vivenciavam o assédio dos capatazes, a objetivação de seus corpos, a violência doméstica e simbólica, além de acumularem as tarefas domésticas e o cuidado dos/das filhos/as. Passavam horas nas filas de pão, enfrentando o rigoroso inverno russo, para que seus/suas filhos/ as pudessem ter minimamente o que comer. Tais situações de exploração e opressão foram se constituindo no combustível fundamental para a reviravolta das mulheres. (TRÓTSKY, 1977). 
A revolução socialista de 1917 trouxe grandes avanços na luta pela igualdade de gênero, especialmente no que tange aos direitos civis e políticos; direito à livre sexualidade; direito ao aborto terapêutico realizado em hospitais públicos e gratuitos, já no ano de 1920, o que fez com que a Rússia se tornasse o primeiro país a garantir tal direito às mulheres. Conquistas ainda na área do trabalho, com salários iguais para trabalhos iguais e socialização do trabalho doméstico e da criação compartilhada das crianças, inclusive como forma de incentivo para a participação das mulheres nas atividades sindicais e partidárias.

Esse processo foi de fundamental importância, ao reconhecer a dupla jornada de trabalho a que eram submetidas as mulheres ao entrarem no mercado de trabalho. Foram criados equipamentos e estruturas sociais, tais como creches, lavanderias e restaurantes públicos que serviam de apoio às mulheres trabalhadoras e se constituíam em um importante passo em direção à sua emancipação, permitindo a liberação destas, das atividades domésticas.

O processo revolucionário e a experiência do Estado Operário proporcionaram um conjunto de avanços no que tange à construção de novas bases legais, culturais e de relações sociais que tinham como horizonte a construção de um novo projeto societário, o comunismo.

Entre outras ações proferidas pelo Estado socialista com relação à emancipação das mulheres, estava a fixação de 8 (oito) horas de trabalho, com pausas para descanso e alimentação; direito a descanso semanal e férias remuneradas; licença maternidade e subsídio de aleitamento; programas e ações especiais de acompanhamento às mães adolescentes; direito à seguridade social, por meio da garantia de pensão e apoio às mulheres idosas, doentes ou que sofreram algum tipo de acidente no trabalho; direito à saúde pública e gratuita, com medicamentos para todos/as e a constituição de um novo Código da Família que legitimava e assegurava as uniões afetivas de fato, concedendo-lhes iguais direitos tal qual o do casamento civil/oficial, especificamente no que concerne à pensão alimentícia em caso de separação ou morte. O novo código buscava superar os moralismos do antigo regime e suprimir todas as formas de opressão existentes contra as mulheres, possibilitando, assim, a participação equitativa das mulheres em espaços anteriormente dirigidos pelos homens, en- 
tre eles, o partido político, as assembleias e reuniões. (GOLDMAN, 2014).

As conquistas históricas da classe trabalhadora expressas na luta das mulheres revolucionárias russas incidiram no marco regulatório do Estado burguês e ecoam no tempo (passado e presente) nos mais diferentes países.

Apesar de já haver manifestações das ideias feministas na primeira metade do século XIX nos países latino-americanos, em particular no Brasil, é somente na passagem entre os séculos XIX e XX, com a absorção da mão de obra feminina à produção social, que tais ideais se materializam nas lutas das mulheres em defesa de melhores salários e condições de trabalho. Os ventos anarquistas e socialistas soprados internacionalmente possibilitam a criação, já no século XX, de organizações feministas, socialistas, liberais e anarquistas em diversos países latino-americanos.

Na realidade brasileira, foi marcante a criação do Partido Republicano Feminista, fundado em 1910, pela professora Leolinda de Figueiredo Daltro, que lutava pela igualdade de direitos jurídicos e políticos para as mulheres. Apesar de se caracterizar como partido, a este não era dado o direito de receber votos, porque era formado exclusivamente por mulheres, funcionando muito mais como uma forma de denúncia da situação das mulheres e de organização destas. Outra organização importante, também, foi a Associação feminista, de cariz anarquista e que teve grande influência na construção das greves operárias de 1918 em todo o estado de São Paulo. Ambas as organizações tinham como mote central a luta pelo sufrágio, conquistado primeiramente no Equador, em 1929, e, no Brasil, nos anos de 1930. (COSTA, 2005).

Apesar das lutas e conquistas, o movimento feminista ainda estava fortemente influenciado por ideias que reforçavam a divisão sexual dos papéis de gênero, estereótipos, reforço às tradições das virtudes domésticas e da maternagem, como uma exigência e um dom por ser mulher. As contradições no processo de construção da consciência de uma nova mulher produziam, concomitantemente, comportamentos de aceitação da diferença sexual, ao mesmo tempo que negavam tal princípio como elemento essencial para a continuação de práticas de discriminação injustificadas. (COSTA, 2005). 
Esse contexto do início do século XX no Brasil demonstra que a luta e organização das mulheres vão possibilitar avanços no campo das conquistas civis, políticas e sociais, assim como limites no campo da articulação e mobilização das pautas feministas para a manutenção dos direitos conquistados historicamente. No contexto atual, e com as transformações societárias em curso no mundo, analisaremos as determinações presentes que impactam o marco regulatório e colocam em movimento a luta de classes, em particular, a mobilização e (re)organização da luta das mulheres trabalhadoras.

\section{NOVO PADRÃO DE ACUMULAÇÃO CAPITALISTA E AS REPERCUSSÕES NO MUNDO DO TRABALHO:} tempos desiguais

A crise do capitalismo contemporâneo instaurada em nível planetário, a partir dos anos 1970, tem afetado o mundo do trabalho, principalmente, através de novas formas de trabalho precário e do aumento do desemprego estrutural. Trata-se de novas estratégias capitalistas que visam à criação de um novo patamar de acumulação do capital, chamada de acumulação flexível que, sob a égide do capital financeiro, caracterizam-se em sua dimensão política, pela vigência das políticas neoliberais expressas em diversas formas, tais como: políticas de privatização, abertura comercial, ajuste monetário e, em sua dimensão estrutural, pelas transformações produtivas - inovações tecnológicas e organizacionais de cariz toyotista.

Em sua dimensão ideológica, a ofensiva do capital se deu pela Queda do Muro de Berlim, em 1989 e pela dissolução da URSS, em 1991, sob a orientação neoliberal. Segundo Alves (1996), as políticas neoliberais e as transformações nos processos produtivos expressam a necessidade intrínseca do capital de impor controle sobre o trabalho, objetivando anular o potencial da classe trabalhadora em seu projeto histórico de superação do capital. Essa reação contemporânea do capital é resultado de uma derrota política da classe operária nos principais países capitalistas, a partir dos anos 1970, que aumentou nos anos 1980, sobretudo através do desemprego, afetando de forma direta as condições de vida das mulheres.

Na América Latina, os anos 1980 são considerados como a década perdida, na medida em que esta foi marcada por perdas econômicas ocorridas através de baixas no Produto Interno Bruto (PIB), aceleração da inflação, estagnação da produção industrial, perda do 
poder de compra dos salários e do nível de empregos. No Brasil, em particular, ficou registrada uma perda econômica incomum em comparação aos cinquenta anos anteriores, em que se obtiveram boas médias de crescimento econômico. Assim, enquanto nos anos 1970 o crescimento do PIB brasileiro foi de $7 \%$, nos anos 1980 o PIB médio recuou para $2 \%$; com efeito, o Brasil teve elevação do déficit público gerada pelo aprofundamento da dívida externa, culminando com a hiperinflação no fim dessa década.

Se nessas décadas, no plano econômico, o país encontrava-se mergulhado num contexto de estagnação, no plano sociopolítico, a sociedade brasileira vivia o período de redemocratização, conduzindo a promulgação de uma nova Constituição Federal (CF), em 1988. Pelo visto, essa nova Carta Magna contou com a participação da classe trabalhadora, homens e mulheres, seja através dos partidos do centro-esquerda, seja através da pressão dos sindicatos e dos movimentos sociais, o que contribuiu para o aprimoramento da legislação referente aos direitos sociais e, dentre outras medidas, estabeleceu a jornada de trabalho de 44 horas semanais, a remuneração das horas extras em valor de $50 \%$ superior ao salário base, o bônus de um terço do salário nas férias, a ampliação da licença maternidade para 120 dias, a licença de paternidade regulamentada em cinco dias, a proteção do emprego em face da automação e o seguro desemprego em caso de desemprego involuntário.

No que se refere às relações de trabalho, a mencionada CF proibiu a interferência do governo nas atividades sindicais, instituiu o direito de greve, além de ter permitido a formação de centrais sindicais e de comissões de fábrica nas empresas com mais de duzentos empregados. No que concerne às políticas públicas de emprego, a novidade posta na referida CF foi a criação do seguro desemprego, em 1986, que integra o conjunto da seguridade social no país.

A referida Carta estabelece o trabalho como um direito inalienável para homens e mulheres, que deve ser garantido pelo Estado, assim como as demais políticas sociais. Nessa perspectiva, o direito ao trabalho aparece como um dos pilares de sustentação da ordem social da mencionada $\mathrm{CF}$, o qual vem se tentando assegurar, mesmo no momento de transformações do mercado de trabalho, isto é, das mudanças no padrão de organização do trabalho instituídas em consonância com as políticas macroeconômicas de estabilização econômica, impostas pelo Fundo Monetário Internacional (FMI) e demais 
organismos multilaterais. Essas políticas delimitaram a intervenção do Estado, provocando o acirramento da questão social em suas variadas expressões, dentre as quais o aumento do desemprego e, ao mesmo tempo, uma nova configuração na inserção das mulheres no mundo do trabalho.

É sob essa lógica que as políticas de trabalho, emprego e renda passaram a ser implementadas no governo do presidente Fernando Henrique Cardoso (FHC). Trata-se de políticas que, no discurso, se propunham a combater a crise do emprego e, consequentemente, a fome e a miséria, porém, essas políticas contam com recursos reduzidos e enfatizam a individualização do problema, reforçando a histórica intervenção residual do Estado brasileiro na questão social.

Em 1994 foram aprovados os contratos atípicos sob a justificativa de redução dos custos de contratação e geração de mais empregos, pois, para os empresários brasileiros, os custos do trabalho impediam as empresas de contratar mais empregados, portanto, competia ao Estado promover reformas, flexibilizando a legislação trabalhista para estimular as taxas de ocupação. Além disso, havia uma preocupação em romper com a rigidez do modelo fordista de gestão do trabalho e do processo produtivo - embora no Brasil, essa rigidez não tenha acontecido na mesma dimensão dos países capitalistas centrais -, permitindo maior liberdade aos empregados na contratação e demissão de pessoal. A retomada da competitividade se constituiu em uma estratégia importante para garantir, política e ideologicamente, a extração dos superlucros, possível apenas por meio da queda dos custos dos fatores de produção. Sendo assim, os ataques aos custos do trabalho, mesmo nos países onde jamais foram significativos, como foi o caso do Brasil, (isto é,) a tentativa de saída para a crise econômica aparece nos discursos políticos como uma questão de ordem natural.

Nesse quadro, as relações trabalhistas foram flexibilizadas e a legislação trabalhista desregulamentada, tendo como consequência o enfraquecimento das organizações representativas dos(as) trabalhadores(as). Ao Estado brasileiro

[...] competia a tarefa de criar os mecanismos para implementar as mudanças necessárias para o enfrentamento da referida crise, mas abstendo-se da responsabilidade de criar políticas de proteção social aos trabalhadores e, fundamentalmente, eliminando as bar- 
O GRITO QUE RECLAMA PAZ: o legado da Revolução Russa para a luta das mulheres

reiras para tornar o trabalho menos oneroso para os empregadores com a redução dos encargos sociais. (OLIVEIRA, 2012, p. 500).

Sob essa ótica, o Estado brasileiro instituiu os contratos por tempo determinado, contrato parcial, temporário, as cooperativas de trabalho, o estágio-trabalho, facilitando, em suma, a demissão pela alteração nas medidas legais e por sentenças normativas. Cabe registrar que em contexto tão adverso para a classe trabalhadora brasileira, no governo do presidente Luís Inácio da Silva (Lula), tramitou um Projeto de Reforma Sindical e Trabalhista que expressava o objetivo de flexibilizar os direitos e precarizar ainda mais o trabalho, visando elevar lucros, sob o discurso da necessidade de modernização e da democratização das relações do trabalho via negociação coletiva.

Constata-se, então, que as medidas adotadas para combater o desemprego no governo do presidente Lula são caracterizadas pela reformulação das já existentes, ou ainda, pela criação de algumas iniciativas inovadoras para atingir o público-alvo definido como prioridade pelas agências multilaterais, como por exemplo, o Programa de Aprendizagem Profissional, regulamentado em 2005 (previsto desde 1943 na Consolidação das leis do Trabalho - CLT, mas que sofreu alteração pelo Decreto-Lei anterior e estabelece que os contratos atuais ainda teriam registro em Carteira de Trabalho e Previdência Social - CTPS); as férias anuais em consonância com as férias escolares; $13^{\circ}$ salário; o Fundo de Garantia do Tempo de Serviço (FGTS) (alíquota reduzida para 2\%) e jornada de seis horas.

Se no governo Lula (2003-2007 e 2007- 2011), seguido do governo Dilma Rousseff (2011 - 2015 e 2015-2016), foram fomentadas políticas que reduziram e ameaçaram o acesso aos direitos dos e das trabalhadoras, sob o discurso do autoemprego e das relações de trabalho precárias, a partir de 2016, com o impeachment da presidente Dilma Rousseff e a ascensão do governo ilegítimo de Michael Temer à presidência da República, o marco regulatório do trabalho, no Brasil, passou a ser desregulamentado de forma acelerada. Nesse contexto, em 11 de julho de 2017 a Reforma Trabalhista (Projeto de Lei da Câmara - PLC no 38 de 2017) foi votada e aprovada, em que pese tenha havido muitas manifestações em vários estados brasileiros e protesto no Senado, realizado pelas senadoras de oposição na tentativa de obstrução da votação.

O impacto dessa medida nefasta juntamente com a Lei da Terceirização, Lei n ${ }^{\circ} 13.429$, de 31 de março de 2017, já aprovada, e o 
congelamento do orçamento público por 20 anos, embora reajustado segundo o índice inflacionário e todas as contrarreformas em curso, a exemplo da Previdência Social, tende, certamente, ao aumento das desigualdades e "[...] da barbarização da vida social no Brasil e, consequentemente, tornarão mais difíceis as condições de resistência da classe trabalhadora." (CONSELHO FEDERAL DE SERVIÇO SOCIAL, 2017, p. 2).

Com efeito, vive-se um retrocesso histórico e civilizatório no que tange ao ordenamento jurídico nacional na relação capital $\mathrm{X}$ trabalho, pois acordos coletivos de trabalho podem retirar direitos legalmente conquistados; as férias poderão ser parceladas em até três períodos, sendo que um deles não pode ser inferior a 15 dias corridos; a jornada de trabalho que hoje é limitada a 8 horas diárias, poderá ser de até 12 horas com 36 horas de descanso, respeitando o limite de 44 horas semanais e o intervalo do almoço pode se limitar a meia hora, além de outros retrocessos previstos na nova legislação. (CONSELHO FEDERAL DE SERVIÇO SOCIAL, 2017).

Tem-se, então, a redução dos custos das empresas com o trabalho, sobretudo pela instituição do princípio da primazia do Negociado sobre o Legislado, no que foi previsto na CLT, na CF de 1988 e nos acordos e convenções coletivas de trabalho, o que "[...] já não figurava entre os mais amplos ordenamentos protecionistas do trabalho, quando comparado a outros países." (CONSELHO FEDERAL DE SERVIÇO SOCIAL, 2017, p. 2). Assim, essas contrarreformas “[...] possibilitarão legalizar a precarização do trabalho, que já era uma prática, embora à margem da lei, fazendo dela a tônica das contratações." (CONSELHO FEDERAL DE SERVIÇO SOCIAL, 2017, p. 2).

Historicamente o grito das mulheres trabalhadoras tem sido vocalizado nas diversas organizações feministas, movimentos de mulheres, coletivos de partidos e sindicatos que, no Dia Internacional da Mulher - 08 de março, denunciam as formas de violência e injustiça a que são submetidas cotidianamente em nosso país. O ano de 2017 entrou para a história com a participação das mulheres nas ruas, nas greves gerais mobilizadas na luta e resistência contra o desmonte de direitos em curso, propiciando a ampliação da sua consciência política.

Em síntese, pode-se afirmar que tais medidas implementadas na atual conjuntura revelam, claramente, o compromisso do Estado 
brasileiro com a ampliação do lucro das empresas capitalistas e com os interesses de várias frações da burguesia nacional e internacional, gerando outros impactos extremamente nefastos para a classe trabalhadora, em particular, para as mulheres trabalhadoras.

4 CONCLUSÃO: cem anos depois - o legado das mulheres trabalhadoras russas para a organização das mulheres trabalhadoras brasileiras

Após cem anos de importantes conquistas realizadas pelas mulheres trabalhadoras russas, indagamos: qual o legado que essas mulheres deixaram para todos/as trabalhadores/as que vivem sob o domínio e o comando do capital? Quais lições precisamos aprender e que se colocam como problemas atuais a serem superados? Quais reivindicações feitas em 1917 ainda são, um século depois, intransponíveis na fronteira da sociabilidade capitalista?

As contradições da sociedade capitalista são experimentadas pelas mulheres com muito mais intensidade. É surpreendente, e por que não dizer, estarrecedor, que a pauta de contestações feitas pelos movimentos feministas, sindicatos de trabalhadores(as), partidos políticos de esquerda e associações de mulheres da atualidade ainda tenha como horizonte as conquistas históricas realizadas na Rússia Socialista, inspirando milhares de mulheres brasileiras a continuarem na trincheira de luta contra o capital.

Porém, é importante ressaltar que "[...] apesar de sua participação concreta em vários momentos da história social, as mulheres e suas lutas nem sempre foram aceitas pelas organizações de trabalhadores." (GURGEL, 2014, p. 58). O reconhecimento do movimento feminista como sujeito político é uma conquista histórica recente e estratégica para a luta socialista.

O cenário atual brasileiro, de aceleração do desmonte, em especial, dos direitos políticos e sociais, nos coloca a necessidade de ação coletiva e organizada para a superação do modo de vida burguês. Sob o eufemismo de modernização do Estado, por meio de reformas, tem-se destruído todo o sistema de direitos sociais garantidos na Constituição Federal Cidadã de 1988, que se materializam seja pela contrarreforma da previdência social, seja pela contrarreforma trabalhista. 
Sob o pretexto de equacionar o rombo na Previdência Social, o governo ilegítimo de Michel Temer promove um ajuste fiscal que atinge em especial às mulheres trabalhadoras, reafirmando o que dizia Simone de Beauvoir ao falar sobre os direitos femininos: "[...] nunca se esqueça de que basta uma crise política, econômica ou religiosa para que os direitos das mulheres sejam questionados. Esses direitos não são permanentes. Você terá que manter-se vigilante durante toda a sua vida".

Tais direitos ameaçados atentam contra o tempo de vida das mulheres, pois com relação ao tempo de aposentadoria, a proposta governamental, sob o pretexto da igualdade de gênero, é igualar as condicionalidades de idade e tempo de serviço entre homens e mulheres para a autorização e liberação da aposentadoria. Considerando a vida real das mulheres trabalhadoras, vimos que isso é pura falácia, na medida em que a realidade cotidiana impõe a essas trabalhadoras duplas ou triplas jornadas de trabalho, já que estas continuam acumulando além do trabalho externo, todo o trabalho doméstico. Segundo o Departamento Intersindical de Estatística e Estudo Socioeconômicos (DIEESE, 2017, p. 2),

[...] a proposta pretende acabar com o princípio da solidariedade social, que está presente na concepção de Previdência desde a promulgação da Constituição Federal (CF) de 1988 e que busca dar tratamento diferenciado a segmentos populacionais com condições desiguais de inserção no mercado de trabalho.

Ao invés de impor uma igualdade formal, esse governo, assim como o anterior, deveria, como fez o Estado Operário russo, possibilitar igualdade de condições reais para essas mulheres, fornecendo e provendo meios e equipamentos públicos e gratuitos, como berçários, creches, refeitórios, lavanderias, que pudessem liberá-las do fatigado trabalho doméstico não reconhecido, não valorizado e não remunerado. No entanto, tais direitos são absolutamente impossíveis de serem alcançados no sistema sociometabólico do capital.

Com relação à contrarreforma trabalhista, tem imperado o negociado sobre o legislado, e os efeitos para a vida das mulheres também serão nefastos. Por estarem em maior número em postos de trabalho absolutamente precarizados e informais, ganharem menores salários em comparação aos homens, a força do negociado irá impor condições de vida mais degradantes. A flexibilização na jornada de trabalho, tendo somente como limitador o total de $220 \mathrm{~h} / \mathrm{mês}$, 
acarretará efeitos deletérios na sobrevida dessas mulheres, considerando suas duplas e muitas vezes triplas jornadas de trabalho diárias.

A proposta aprovada inclui prolongamento da jornada de trabalho, restrição do tempo de intervalo, divisão das férias, supondo de fato existir a livre negociação entre capital e trabalho. Essa livre negociação vai aprofundar ainda mais os processos de desigualdade social, em especial para as mulheres trabalhadoras, na medida em que coloca o poder do acordo nas mãos dos patrões, uma vez que o crescente exército industrial de reserva impõe-se no processo de superexploração da força de trabalho.

Para as mulheres, em particular as mulheres negras que se encontram numa escala maior de superexploração, os efeitos da contarreforma são mais perversos. O legado da atuação do patriarcado na história brasileira mostra sua face mais catastrófica, já que uma parcela significativa destas, ainda se encontra presa ao trabalho doméstico que, há bem pouco tempo, foi igualado aos direitos trabalhistas dos/das trabalhadores/as rurais e urbanos, por meio da Emenda Constitucional $\mathrm{n}^{\circ} 72$, de 2 de abril de 2013, o que não significa que tenha se efetivado. Ou seja, o sonho da carteira assinada, da garantia de recebimento de um salário mínimo, do direito às férias, do direito ao tempo de intervalo e da negociação coletiva, torna-se, apesar da aprovação da emenda, irrealizável.

Pensar no contexto atual e na intensificação da precarização e degradação da classe trabalhadora, em especial das mulheres, remete-nos à memória das péssimas condições de vida das mulheres russas no início do século XX.

As perspectivas de superação dessa situação têm no legado da Revolução Russa, aprendizados e possibilidades profícuas. A separação de cem anos do tempo de ontem para o tempo de hoje nos coloca, nos provoca e nos convoca a reeditarmos a história dessas lutadoras, reconhecendo sua ousadia, bravura, determinação, força e firmeza. A história delas pode ser a nossa história e o cenário atual tão árido que se apresenta a todos/as nós, nos impele a resistir e nos oferece a possibilidade de sonharmos com novos outubros, acreditando que um dia estaremos vivendo igualdades e liberdades num mundo emancipado.

Parafraseando Camus, em o mito de Sísifo será que a realização do absurdo exige suicídio? Não. Exige revolta! 


\section{REFERÊNCIAS}

ALVES, G. Nova Ofensiva do capital, crise do sindicalismo e as perspectivas do trabalho: o Brasil nos anos noventa. In: TEIXEIRA, F. J. S. et al. Neoliberalismo e reestruturação produtiva e reestruturação produtiva. São Paulo: Cortez; Fortaleza: Universidade Estadual do Ceará, 1996.

CONSELHO FEDERAL DE SERVIÇO SOCIAL. A contrarreforma trabalhista. CFESS Manifesta, Brasília, DF, ed. esp., 12 jul. 2017. Disponível em: $<$ http://www.cfess.org.br/js/library/pdfjs/web/viewer. html?pdf=/arquivos/2017-CfessManifesta-ContrarreformaTrabalhista. pdf $>$. Acesso em: 15 jul. 2017.

COSTA, A. A. A. O movimento feminista no Brasil: dinâmicas de uma intervenção política. Revista Gênero, Niterói, v. 5, n. 2, p. 9-35, sem. 2005. Disponível em:<http://www.revistagenero.uff.br/index.php/ revistagenero/article/viewFile/380/285>. Acesso em: 24 out. 2017.

DEPARTAMENTO INTERSINDICAL DE ESTATÍSTICA E ESTUDO SOCIOECONÔMICOS. As mulheres na mira da reforma da Previdência. São Paulo, mar. 2017. (Nota Técnica, n. 171). Disponível em:<https://www.dieese.org.br/notatecnica/2017/ notaTec171MulherPrevidencia.pdf>. Acesso em: 15 jul. 2017.

GOLDMAN, W. Mulher, Estado e Revolução: política familiar e vida social soviéticas, 1917-1936. 1. ed. São Paulo: Boitempo: Iskra Edições, 2014.

GURGEL, T. Feminismos no Brasil contemporâneo: apontamentos críticos e desafios organizativos. Temporalis, Brasília, DF, v. 14, n. 27 , p. 57-76, jan./jul. 2014.

KONDER, L. O que é dialética? 22. ed. São Paulo: Brasiliense, 1991.

OLIVEIRA, E. A. de. A política de emprego no Brasil: o caminho da flexisegurança. Revista Serviço Social e Sociedade, São Paulo, n. 111, p. 493- 508, jul./set. 2012.

SOUZA, L. E. V. de. A recepção alemã à Revolução Russa de 1905. 2012. 319 f. Tese (Doutorado em Sociologia) - Departamento de Sociologia, Faculdade de Filosofia, Letras e Ciências Humanas, Universidade de São Paulo, São Paulo, 2012.

TRÓTSKY, L. A história da Revolução Russa. 2. ed. São Paulo: Paz e Terra, 1977. v. 1, cap. VII.

ZETKIN, C. La cuestiónfemenina y la lucha contra el reformismo. Barcelona: Anagrama, 1976. 